\title{
RELATION BETWEEN RESULTS OF THE LEARNING POTENTIAL TESTS AND STUDY RESULTS
}

\section{Jana Kubanová, Bohdan Linda}

\section{Abstract}

The paper deals with one of problems of universities education - with problem of admission process. The classical entrance examinations, common in the last years, were nowadays substituted by modern method - by learning potential tests (LPT). The question whether it is possible to forecast the study results on the base of the LPT results arises at this moment. Two samples of students are analysed in this paper, students who were admitted in the years 2010 and 2011. The relation between study results and results of LPT provided by the private company Scio is analysed in this paper. The hypothesis, that the better results in learning potential test are the warranty of better study results at the university, was examined. To verify this hypothesis both correlation and regression analysis were used. The insignificant correlation was detected between results in learning potential test and study results. Similarly the regression coefficient had value close to zero. The relevant dependence between the learning potential test and study results haven't been demonstrated and the hypothesis showed to be quite incorrect.

\section{Key Words}

Admission process, Gama correlation, grade average, Kendal's correlation tau, Learning potential tests (LPT), regression coefficient, Spearman's correlation coefficient
University of Pardubice jana.kubanova@upce.cz

\section{ARTICLE INFO}

Article type

Full research paper

doi: 10.7160/eriesj.2012.050302

Article history

Received: July 2, 2012

Received in revised form: September 27, 2012

Accepted: September 28, 2012 Available on-line: September 30, 2012

Kubanová, J., Linda, B. (2012) "Relation between Results of the Learning Potential Tests and Study Results", Journal on Efficiency and Responsibility in Education and Science, Vol. 5, No. 3, pp. 125-134, ISSN 1803-1617, [on-line] www.eriesjournal.com/_papers/article_178.pdf 


\section{Introduction}

Each university and each educational institution strives to gain the best candidates for study. One important step is to set correctly the condition of the admission procedure. The practice that was realised many years ago was that the students, who were interested to study at any faculty, had to pass the entrance examination just at the concrete selected faculty. This entrance examination was in relation with the subjects studied at the faculty, they were different for philosophical faculties, different for economical, mathematical, technical faculties and so on. The contemporary trend is to substitute the classical entrance examinations by any complex test - by the tests that should check up the student's disposition and ability for successful study. Such kind of test is called learning potential tests (LPT). These tests are provided, among other organisations and companies, by the private company Scio. It seems to be very comfortable to transfer a lot of work connected with preparation, own realisation and last but not least responsibility connected with admission process on other subject, at this case the private firm. The other visible advantage for the university is that the financial costs bear especially the applicants; the university contributes by negligible amount of money.

On the other hand it is necessary to verify the quality of the tests, their validity and reliability. The promotional materials (see www.scio.cz) of above mentioned company declare that there is the statistically significant relation between the learning potential test results and study success, which should indicate the required validity. They published, among other things, the following graph as verification of their statement.

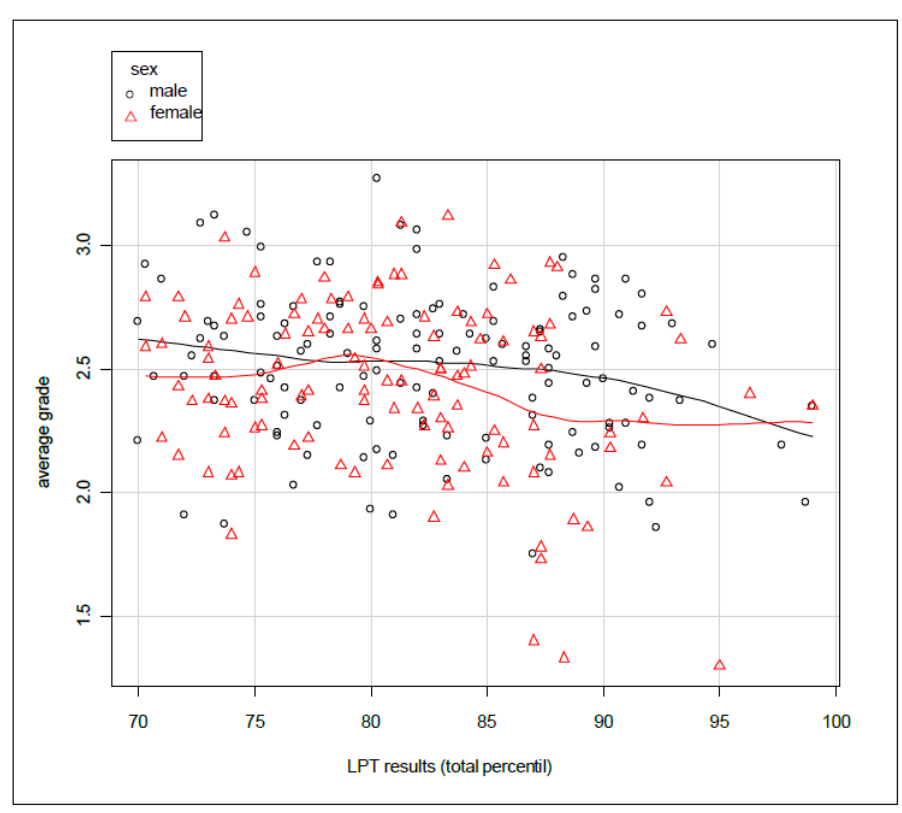

Fig. 1: Relation between the results of LPT and study results during 1st till 5th term at the Faculty of Economics, University of Economics, Prague. Source: www.scio.cz, s.r.o. (14.11.2011).

The fig. 1 presents study results of the students with LPT results between 70 th and 100 th percentile. It is evident that average grade is between 2,0 and 3,0 almost equally distributed. This figure and our experience evoked our intention to study this problem in a more detailed way. Our experiences with students, who were taken to study according LPT criterion are rather different than it is described in above mentioned study. The goal isn't also to compare the results at the Faculty of Economics, University of Economics, Prague and University of 
Pardubice, but to solve the question whether exist any relevant relation between LPT results and study results.

The question of learning potential assessment is discussed for a long time. A great number of written scientific studies and a lot of developed tests relate to solution of this problem. The measurement of learning potential requires a number of investigations, the accurate methodology and wide theoretical background not only in psychology. For example a number of techniques to assess learning potential, basis of the construction of the learning potential tests, their validity and methodology have already been described by Hamers, Ruijssenaars and Sijtsma (1992).

The complex view to knowledge is given in the book System Approach to knowledge modelling, resulting from research of the authors Dömeová, Houška and Beránková Houšková (2008). The book shows the presents state of knowledge science, different definitions of knowledge, and requirements of changes in managerial behaviour. The knowledge supporting the decision making process is emphasized. The positive evaluation and review of this book is given by Mildeová (2008).

The preferences and ideas of potential applicants for university education are solved by Husák, Volkánová (2011). The authors use the quantitative empirical research to examine the main factors which influence the decision-making process of potential applicants for university education.

The problem of distinction between conventional academic predictors and performance-based tests is solved by authors Tanilon, Vedder, Segers, Tillema (2011). The incremental validity of a performance-based test over conventional academic predictors is presented. The result of this study is that the performance-based test has incremental validity in predicting academic performance. The performance-based tests demonstrate potential as an academic predictor.

This paper follows up with investigation presented by Kubanová, Linda (2012), the authors extended their work for the results of the LPT from the year 2010. It enables to monitor the assumed relation during a longer period.

\section{Materials and Methods}

The investigation of the relation between results of the learning potential tests and study results was realized in two successive years, after the students were taken to study according to the results of the LPT test. The first data file is created by the results of 812 students of the Faculty of Economics and Administration of the University of Pardubice, who were taken to study after LPT and entered university in 2010 (the data file is marked I/2010). The lower limit for student's admission was $20^{\text {th }}$ percentile. That limit is usually stated by the dean of the faculty. During two years long period the study results as

- grade average after the first term,

- grade average after the second term,

- grade average after the third term,

- result from the subject mathematics 1 ,

- result from the subject microeconomics,

- result from the subject mathematics 2,

- result from the subject microeconomics were observed and processed.

The grade average describe the study results in a sufficient way, the reason of selection of four last items is that microeconomics and macroeconomics are the subjects of general basis at all economical faculties, mathematics 1 and mathematics 2 are the 
subjects, that cause the biggest problem for students and set of all these items reflect the study potential of students.

The second file has been created by the results of 552 students of the same faculty, who were taken to study after LPT and entered university in 2011(the data file is marked II/2011). The lower limit for student's admission was $16^{\text {th }}$ percentile. The result of investigation started to be analyse during spring 2012, for this reason we kept at disposition only study results as

- grade average after the first term,

- result from the subject mathematics 1 ,

- result from the subject microeconomics.

The statistical methods, used for processing and evaluation of the statistics data, are described in Hendl (2004) and Kubanová (2008).

The original intention of this paper was to test hypothesis about Pearson's correlation coefficient and hypothesis about the coefficients of the regression lines. The assumption for application of these tests is normal distribution of population as pointed by Pacáková et al (2012). Both histograms in the figure 2 present frequencies of the students who were taken to study according to the points obtained in LPT in the year 2010 and 2011. The shape of both of them is very similar. The histograms suggest that the data are not from population with normal distribution. This assumption was verified both chi-square, the $p$ values were 0,00012 and 0,00016 . The Lilliefors test showed similarly small $p$-value.

For this reason we could not use the methods based on the assumption of normal distribution of data. That is why the nonparametric methods and the methods of descriptive statistics were used for evaluation of the stated problem.

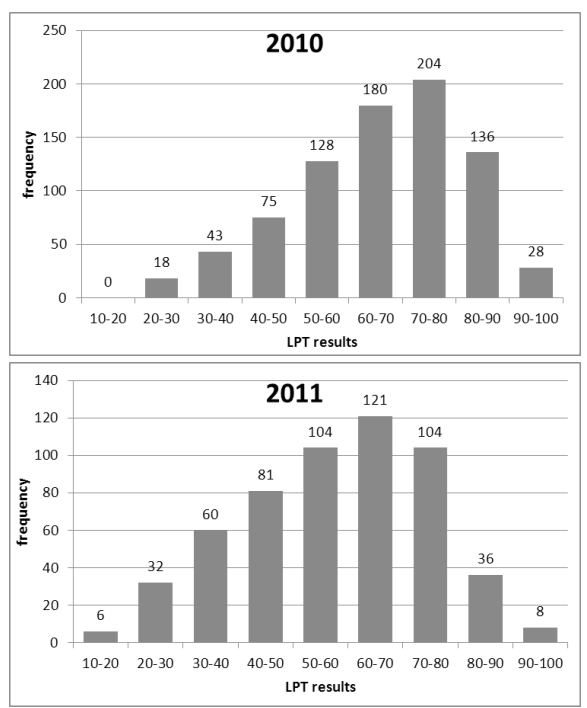

Fig. 2: Histograms - numbers of students that were admitted to the study according to the LPT in the year 2010 (the left histogram) and in the year 2011 (the right histogram)

\section{Results and Discussion}

\section{Correlation}

The relation between the results of LPT and study results is presented in the correlation coefficients. Four different ways of correlation coefficient calculation were used; the first three are nonparametric due to the character of data (Spearman's correlation coefficient, Gama correlation, Kendal's correlation tau), the fourth one is the classical Pearson's correlation coefficient. This last mentioned Pearson's correlation coefficient 
was calculated with cognizance that the assumption of normality is not satisfied, but this coefficient is the mostly presented correlation coefficient used by many authors and it can help to compare the results. On the other hand 812 and 552 observations are enough to get reliable conclusions.

The stated table of the correlation coefficients include the correlation coefficients that express the relation between following items in the data file $\mathrm{I} / 2010$ :

- the LPT results and the grade average after the first term of study (average 1),

- the LPT results and the grade average after the second term of study (average 2),

- the LPT results and the grade average after the third term of study (average 3),

- the LPT results and results of the examination of the mathematics 1 (mathem1)

- the LPT results and result of the examination of the microeconomics (microec)

- the LPT results and results of the examination of the mathematics 2 (mathem2)

- the LPT results and results of the examination of the macroeconomics (macroec)

for the students, who entered to university in the year 2010.

Regarding to the shorter period of investigation for the second group of students, who entered university in the year 2011, the correlation matrices include the correlation coefficients that express the relation between items in the data file II/2011:

- the LPT results and the grade average after the first term of study (average 1),
- the LPT results and results of the examination of the mathematics 1 (mathem1)

- the LPT results and result of the examination of the microeconomics (microec)

\begin{tabular}{|l|c|c|c|c|c|c|c|c|}
\hline & $n$ & Spearman & $p$ & Gama & $p$ & Kendal & $p$ & Pearson \\
\hline average 1 & 714 & $-0,123$ & 0,001 & $-0,091$ & 0,001 & $-0,086$ & 0,001 & $-0,128$ \\
\hline average 2 & 498 & $-0,267$ & 0,000 & $-0,187$ & 0,000 & $-0,182$ & 0,000 & $-0,278$ \\
\hline average 3 & 387 & $-0,181$ & 0,000 & $-0,125$ & 0,000 & $-0,123$ & 0,000 & $-0,196$ \\
\hline matem1 & 688 & $-0,166$ & 0,000 & $-0,192$ & 0,000 & $-0,131$ & 0,000 & $-0,175$ \\
\hline microec & 711 & $-0,130$ & 0,001 & $-0,123$ & 0,000 & $-0,098$ & 0,000 & $-0,135$ \\
\hline matem2 & 178 & $-0,095$ & 0,250 & $-0,078$ & 0,180 & $-0,067$ & 0,180 & $-0,132$ \\
\hline macroec & 498 & $-0,194$ & 0,000 & $-0,177$ & 0,000 & $-0,147$ & 0,000 & $-0,204$ \\
\hline
\end{tabular}

Tab. 1: The correlation coefficients - relation between items of the sample $\mathrm{I} / 2010$

\begin{tabular}{|l|c|c|c|c|c|c|c|c|}
\hline & $n$ & Spearman & $p$ & Gama & $p$ & Kendal & $p$ & Pearson \\
\hline average 1 & 502 & $-0,105$ & 0,014 & $-0,079$ & 0,007 & $-0,076$ & 0,007 & $-0,116$ \\
\hline matem1 & 442 & $-0,129$ & 0,002 & $-0,149$ & 0,000 & $-0,102$ & 0,000 & $-0,147$ \\
\hline microec & 465 & $-0,168$ & 0,000 & $-0,159$ & 0,000 & $-0,128$ & 0,000 & $-0,161$ \\
\hline
\end{tabular}

Tab. 2: The correlation coefficients - relation between items of the sample II/2011

The number of students (tables 1 and 2) is different for each pair of observed variable, because we considered only students, who had any results. The results of the students, who finished their studies during the first term without any grade or students who never tried to pass the exam, are not included in this calculation. We can see in the tables 1 and 2 the calculated values of the Spearman's, Gama, Kendal's and Pearson's correlation 
coefficient between LPT and the grade average respectively between LPT and selected study subjects. All used methods of the correlation coefficient calculation show that the correlation dependence nears the zero, even though the corresponding $p$-values suggest that the zero hypothesis (that the correlation coefficient equals to zero) should be rejected at the usual significance levels. It should be noted, however, the wellknown statistical fact that when the great number of data is processed then the zero hypothesis (i.e. $\mathrm{Q}=0$ ) is rarely, almost never, cancelled. The fact that the correlation coefficient differs from zero needn't indicate the existence of the relevant relation between investigated variables. In our case the calculated correlation coefficients lie with two exceptions from $-0,067$ to $-0,196$, which signify according to accredited statistical literature very weak correlation relation.

Hendel (2004) states that values 0,1 - 0,3 predicates of very week correlation relation, 0,3-0,7 of middle relation and 0,7-1,0 strong relation (page 246). When the values of the correlation coefficient are close to zero, we can make conclusion, that there is no correlation relation between the results of the LPT and study results. It means that the excellent results in LPT don't guarantee that the student will have good results in his/her study and that the LPT result can't reliably forecast the study success, as pointed by Hendl (2004). The relation between LPT and study results expressed by the grade average and study subjects is considered as insignificant.

\section{Study failure and LPT results}

The first group, that was analysed, was compounded of 812 students, who started their study at the University Pardubice in 2010 (group I/2010). 155 students finished their study even in the year 2010. 248 students had to finish their studies after the first year from the reason of bad study results (during September and October 2011). 16 students had to finish their study during January and February 2012, the reasons of all of them were the bad study results. Generally, only 393 students (48\%) continue their study at the university till now from the total number 812, who were accepted after the LPT.

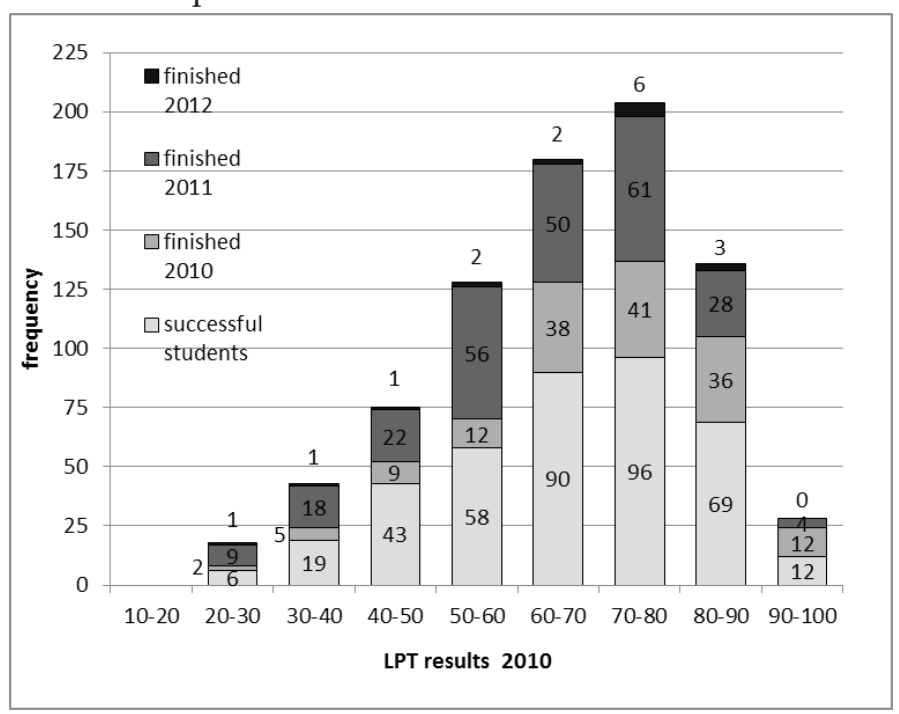

Fig. 3: Histogram - numbers of the successful and unsuccessful students who finished their study in 2010, 2011 and 2012 according to the LPT

It was the reason why we analysed the number of the unsuccessful students depending on the results of LPT. This reality is presented in the figure 3 . We can see the small number of unsuccessful students in the interval $20-30$ LPT points (2 in 2010, 9 in 2011, 1 in 2012) and similarly $90-100$ (12 in 2010, 
4 in 2011, 0 in 2012). The most unsuccessful students were absolutely from the group with LPT result 70-80 points (41 in 2010, 61 in 2011, 6 in 2012, totally 108, which are more than one half). The group of 155 students (finished in 2010) is discussible, because some individuals finished their study at the University of Pardubice in order to study at any other university, in which were probably additionally accepted. But the majority of these students finished, because they found that this study is out of their capabilities.

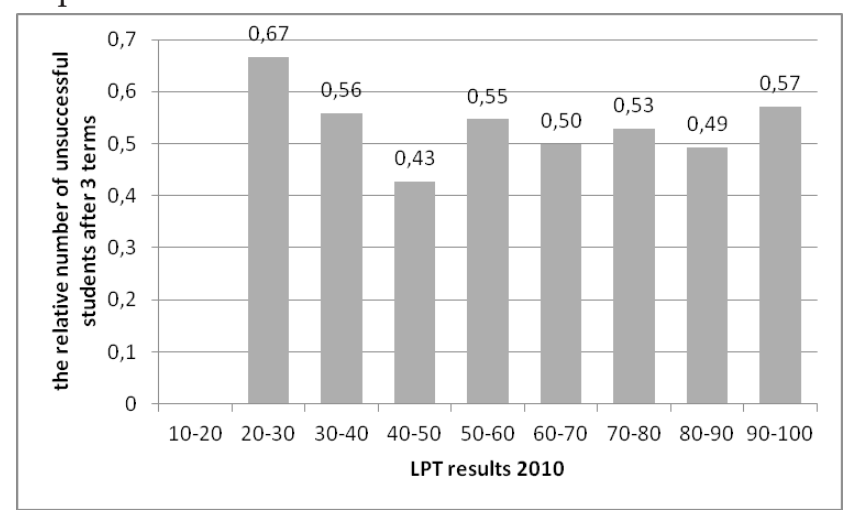

Fig. 4: Histogram - relative values of the unsuccessful students after 3 terms

The relative numbers of unsuccessful students (see figure 4) are very similar for all LPT results range. This relative value seems to be higher for 20-30 LPT points $(0,67)$, but it was only 18 students in this group (12 unsuccessful), which is not significant with regard to all group of 812 students. We can see from the figure 4 that the better result in LPT doesn't mean the bigger success in study, it means that there is not any relation.

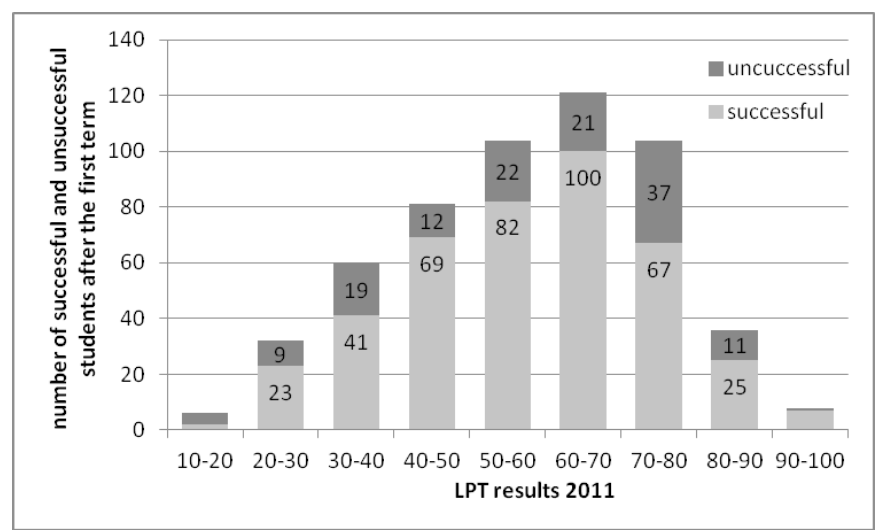

Fig. 5: Histogram - numbers of the successful and unsuccessful students after the first term according to the LPT in 2011

The second group of 552 students, that was analysed, started their study at university in 2011 (group II/2011). 136 students had to finish their studies after the first term from the reason of bad study results. This reality is presented in the figure 5 . We can see the small number of unsuccessful students in the interval $10-20$ LPT points (4) and similarly $90-100$ (only 1). But it is not significant, because a small number of students with this LPT result were admitted to the study ( 6 in the interval 10 - 20 LPT points and 8 - in the interval $90-100$ LPT points). On the other hand there were 37 unsuccessful students who reached 70-80 LPT points. This discrepancy led us to consider the relative values. The first and the last interval, containing the small number of data, are not illustrated in the histogram. 


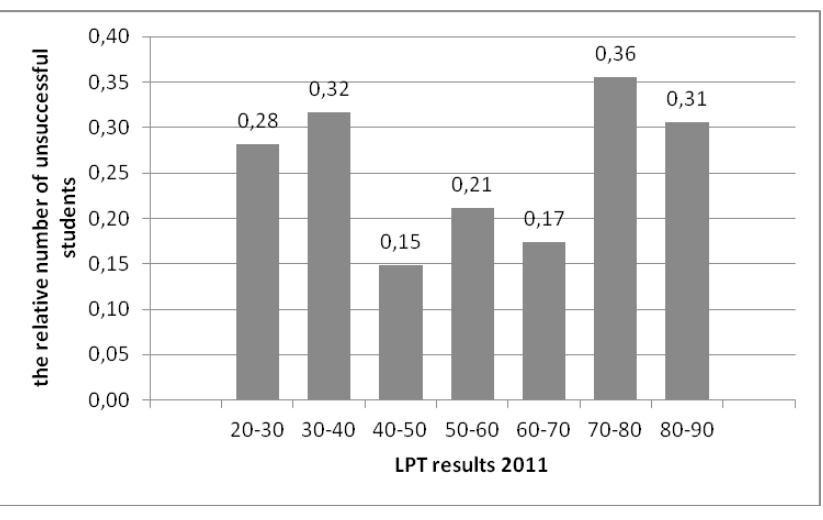

Fig. 6: Histogram - relative values of the unsuccessful students (number of the unsuccessful students/number of admitted students to the study) according to the LPT

We can see in the figure 6 that the worse result in LPT doesn't mean the bigger failure in study, it means that there is not any relation.

The number of unsuccessful students, who were accepted after good results of LPT seems to be too high, that is why we solve the question, whether good result of LPT is connected with good study results. Unfortunately, the answer is evidently negative; the percentage of unsuccessful students don't systematically differ on various results of LPT.

\section{Regression analysis}

We saw in the previous paragraph that the LPT results can't be by far considered to be the important factor for study success. It was demonstrated by the help of sample correlation coefficient. Even this mentioned fact we dealt with the regression analysis. We can see in the figure 7 four scatter charts that express the relation between the LPT results and study results - concretely the grade average after the first, second and third term for the students who were accepted in 2010 and the grade average after the first term for the students who were accepted in 2010. In the case of the linear dependence the points should be distributed along the regression line. We can see for the first sight that the values (points) are almost randomly distributed in the rectangle defined by $20^{\text {th }}$ and $90^{\text {th }}$ LPT point on the $x$-axis and by 1,5 and 4 value on the $y$-axis and they don't show any clear tendency. It means that there is not systematically difference in study results in dependence at LPT results. We can reach the similar conclusion when we try to fit a regression line through measured data.
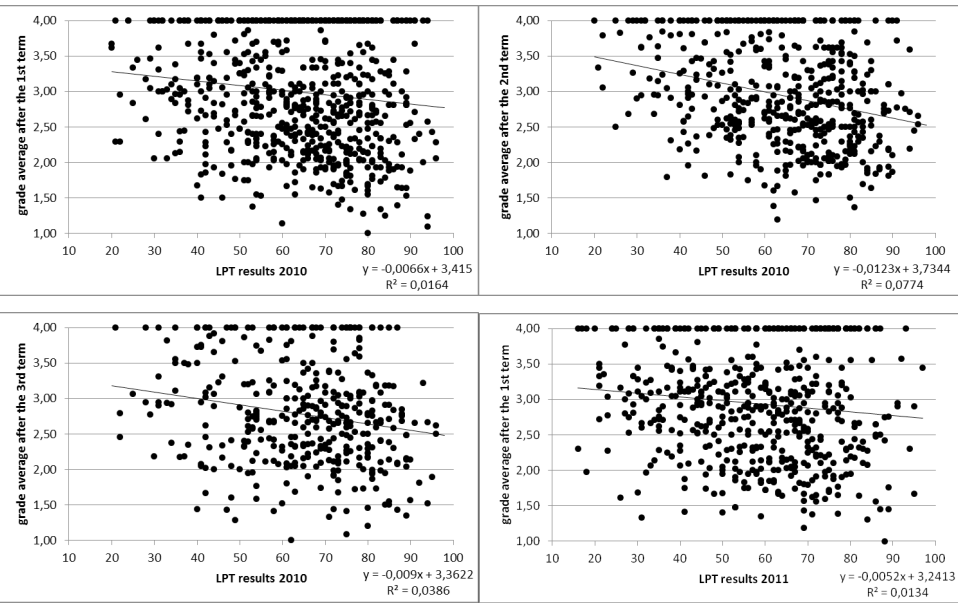

Fig. 7: The scatter chart- relation between LPT results and the grade average 
The equation of the linear regression functions are

- $y=-0,0066 x+3,4150$

- $y=-0,0123 x+3,7344$

- $y=-0,0090 x+3,3622$

- $y=-0,0052 x+3,2413$

Parameters of the regression line were calculated by the help of the least square method. The results concerning the regression coefficient are only stated, not tested, so it wasn't made the obligatory step checking the fulfilment of required assumptions. The slopes of all stated regression lines $(-0,0066 ;-0,0123 ;-0,009$; $-0,0052)$ are so small, that we can say that they are almost equal to zero. Then the regression line seems to be the constant function and the study results don't differ for individual values of LPT. The presented determinacy index is close to zero as well, it shows that the linear regression function is improper for this relation, but it is complicated, but even impossible to find any meaningful relation, when we observe the scatter diagram. Although the relation between the LPT results and grade average was not found, we analysed results of individual subject in relation to LPT results.

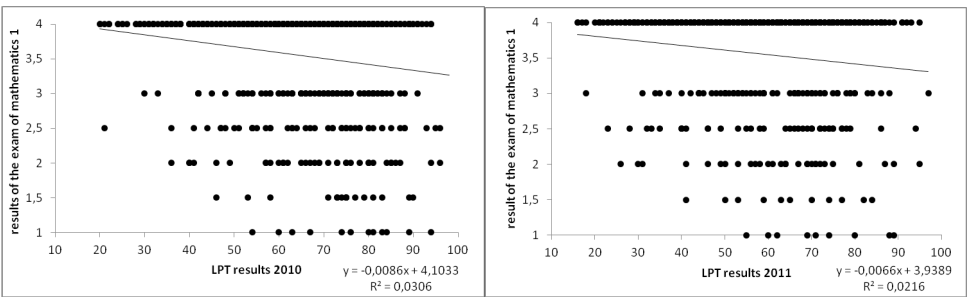

Fig. 8: The scatter chart - relation between LPT results 2010 and 2011 and mathematics results
The figure 8 describes results in the examination from mathematics in relation to LPT results for both examined groups of students. We can see that results 1 and 1,5 could be connected with LPT result over 50, but it is lack of data with this result (2010 only 12, 2011 only 9 excellent evaluation of students). The other results $(2 ; 2,5 ; 3)$ are almost randomly distributed among LPT results from 20 till 90. The special attention can be given to the result 4 from mathematics, it means to the not successful students. These results are again almost randomly distributed between 15 and 95 values of LPT. It is evident that classifications "failed" get students with bad LPT result the same way as students with excellent LPT result. Very interesting is as well the concordance rate of both charts, although two different samples (groups of students) were analysed. It gives impression as if the samples had been selected randomly even though they were actually selected according to the result of the LPT provided by Scio company.
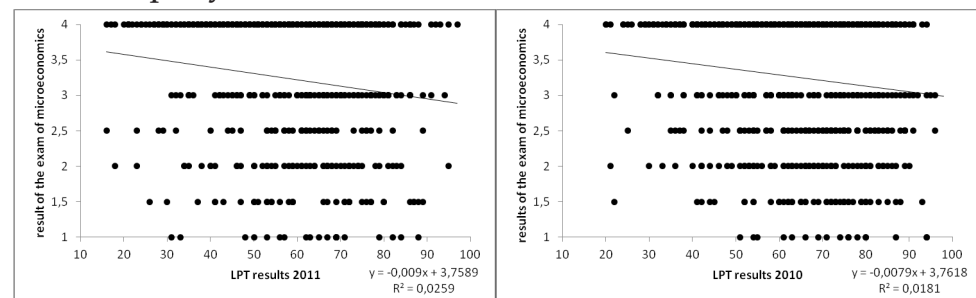

Fig. 9: The scatter chart - relation between LPT results 2010 and 2011 and subject microeconomics

The figures 9 and 10 are very similar to the figure 8 , the conclusions can be quite identical, in neither case we found reason to claim that the result of any exam is connected with any result of LPT. 


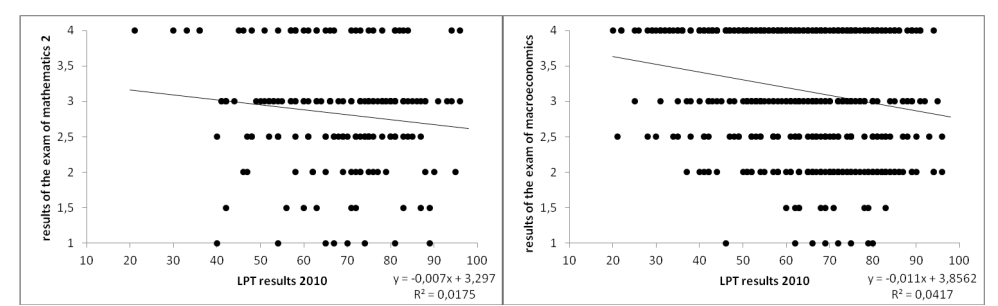

Fig. 10: Relation between LPT results 2010 and subjects mathematics 2 and macroeconomics

\section{Conclusion}

The above stated results show that it is not possible to predict reliably the study results on the base of the LPT results. It is not possible to claim that the learning potential tests (LPT) detect the real assumption for study, also study potential.

It means that the similar results would be got by the random sampling; also the educational institution would select the candidates for study quite randomly and the final results wouldn't be probably different.

It is possible to recommend in the end of this study that the universities should analyse the success of their students in dependence of LPT and in the case of the similarity to these presented results they should try to find any different way of admission process or to go back to the classical entrance examination.

\section{References}

Dömeová, L., Houška M., Beránková Houšková, M.(2008) System Approach to knowledge modelling, Hradec Králové: Graphical Studio Olga Čermíková, ISBN 978-80-86703-30-5.
Hamers, J.H.M., Ruijssenaars A.J.J.M., Sijtsma K. (1993) Learning Potential Assessment, Theoretical, Methodological, and Practical Issues: Amazon.co.uk, ISBN 90-265-1238 4.

Hendl, J. (2004) Přehled statistických metod zpracování dat, Praha: Portál, ISBN 80-7178-820-1.

Husák, J., Volkánová, M. (2011), "Preferences of Potential Applicants for University Education and the "Learning Economy", Journal on Efficiency and Responsibility in Education and Science, Vol. 4, No. 2, pp. 77-88, ISSN 1803-1617.

Kubanová, J. (2008) Statistické metody pro ekonomickou a technickou praxi. Bratislava: Statis, ISBN 978-80- 85659-47-4.

Kubanová, J., Linda,B. (2012) "Learning Potential Tests and Study Success", Proceedings of the $9^{\text {th }}$ International Conference Efficiency and Responsibility in Education, Czech University of Life Sciences Prague, pp. 279-286, ISBN 978-80-213-2289-9.

Mildeová, S. (2008) "Professional monograph review", Journal on Efficiency and Responsibility in Education and Science, Vol. 1, No. 2, pp. 44-52, ISSN 1803-1617.

Pacáková et al (2012) Štatistická indukcia pre ekonomov, Bratislava: Ekonóm publishing.

Tanilon,J., Vedder P., Segers M., Tillema H. (2011) “Incremental validity of a performance-based test over and above conventional academic predictors", Learning and Individual Differences, Volume 21, Issue 2, April 2011, Pages 223-226. http://dx.doi.org/10.1016/j.lindif.2010.12.005

Analýza úspěšnosti studia na Národohospodářské fakultě VŠE a Praze a její predikce testem OSP. Wrote up: www.scio.cz, s.r.o. (14.11.2011). Data material: Faculty of Economics, University of Economics, Prague. 